so, for the present, we have performance arousal, physiological arousal, subjective arousal and finally "actual" arousal. Individual difforences are a tiresome source of error; in discussing experimental design it is stated that ". . . there is a certain amount of variability between people which cannot be removed" (p. 44).

Given these self imposed limitations of approach, however, Poulton has done his job. Anybody interested in brief summaries of what controlled experiments have revealed about any of twenty-odd separate human stressors will find it in his book. The last chapter describes what little is known about pairs of stressors acting together. What happens in the normal human condition of different individuals pursuing different goals with different drives under a range of stressors is still anybody's guess.

W. T. Singleton

\section{KNOTTY PROBLEMS}

\section{Knots}

By R. D. Laing. (World of Man: a Library of Theory and Research in theHuman Sciences.) Pp. 90. (Tavistock: London, September 1970.) $30 s$.

IT is strange to find what appears at first sight to be a collection of poems among a series entitled "World of Man: A Library of Theory and Research in the Human Sciences", but then R. D. Laing is noted for his pursuit of novel forms of inquiry into the human psyche. The poems displayed in this book are for the most part descriptions of the bizarreries and intricacies of attitude that are commonly expressed in the course of human interaction. The result is a series of snapshots which capture, in the precise form of bold type on white paper, the strangled, semiconscious, less-than-verbalized arguments we trap ourselves in.

The poems are word games of occasionally vital personal importance, during which statement and answer are related by a thread of confused yet justifiable personal logic.

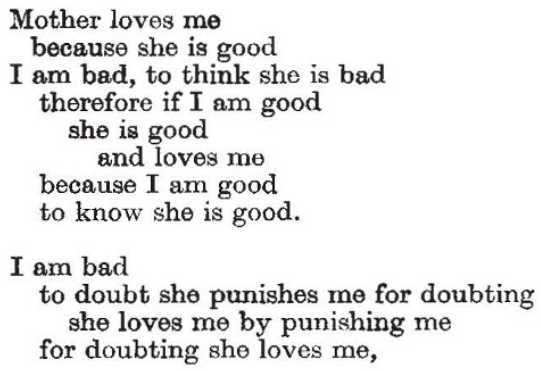

and so on.

Wo all oxperience tho urgent need to express highly complex feelings and situations when relating to another person. This need is often inadequately fulfilled, the words becoming bogged down in an impasse, a full circle, a knot. How often this has turned a conversation into an escalating conflict. We recognize the familiar truth that the reprosentations possess with a sense of uncomfortable amusement:

She is devoured, by him being devoured by her devouring desire to be devoured

He is devoured by her being devoured by him not devouring her.

The episodes recreated hero are like a picture of a hand finishing the outlines of another hand which is finishing the outlines of the first. Laing's drawings have this typo of paradoxicality, but they are not trompe l'oeil fantasies but reproductions of actual situations. What is impossible in physical space is not only possible but common fare in intrapersonal space. We constantly find ourselves portraying another's act of portraying us. It is in terms of our notions of the other's portrait of us that we have to constitute our own self-portrait. But the other's portrait of us is itself based on the other's estimate of our own self-portrait, and so on. 'Thus, in order to provide oursolves with a self-image and an other-image which will enable us to determine the way we are going to act towards them, we have to go through operations of enormous logical complexity. It is not surprising that sometimes the fuses blow and we end up onmeshed in self-deception and circularity. This idea, explored in The Politics of Experience, is displayed in Knots in a more sophisticated form, stimulating the reader to an extensive logical and metaphorical introspection.

For this reason the book is entertaining to read, and, in proportion as the passages impress upon us their familiarity, it is revealing. There are places, however, where the mode of presentation and the presenter seem to be more in focus than what is being presented. But then it is very difficult for somebody else to provide us with our mental belongings without putting their fingerprints all over them. It may be philistine to wonder whether certain parts of the book are conceived with slightly more levity than would seem consistent with the book's apparent general aim, but again, some will find that heartening.

Steve Fulder

\section{SOCIOLOGY OF CRIME}

\section{Crime and Its Treatment}

By John Barron Mays. (Aspects of Modern Sociology: The Social Structure of Modern Britain.) Pp. 164. (Longman: London, October 1970.) $30 s$ boards; $15 s$ paper.

Trins elementary but well informed text summarizes current criminological ideas in a concise and stimulating manner that should have a wide appeal to students. The realistic emphasis on the factual content of criminological data is helpful. It is pointed out very early on that ninety per cent of criminal convictions are for offences against property, which are predominantly committed by working class males, many of thom schoolboys. The complementary quality of sociological and psychological theories is also clearly demonstrated. On the one hand, property crime may be said to be part and parcel of the conventional way of life in the economically poor urban neighbourhoods. On the other hand, whether any particular child in the working-class ghetto becomes an official delinquent is largely decided by the quality of his home life and upbringing.

Most of the adult habitual offenders known to the prison authorities are men whose personality deficiencies render them vulnerable to temptation. They are exploited as "jackals of the trade" by the small but troublesome minority of more competent, organized, professional criminals who are responsible for an increasing number of well planned and profitabie coups. These organized criminals pose a threat to the welfare of the community and present a problem altogether different from that of the rank and file of more or less pathetic cases that make up the clientele of social workers and prison administrators.

The relative immunity of the affluent classes from criminal convictions is discussed sceptically. Embezzling, tax evasion and business fraud, when found out, are often dealt with as if they were not really crimes at all. The offenders themselves and their associates would never put themselves in the same category as the common burglar, although the amounts taken may be incomparably greater.

Professor Mays brings an experienced and humane approach to bear on these emotional topics. In the section on penal treatmonts he discusses frankly the absence of convincing evidence of the effectiveness of any particular panacea. At the same time he wisely points out "What we do does not seom to make very much difference either way, but to do nothing is to resign ourselves to despair and 